\title{
Microwave-Assisted Three-Liquid-Phase Extraction of Diosgenin and Steroidal Saponins from Fermentation Broth of Dioscorea zingiberensis C. H. Wright
}

\author{
Lin LIU* \\ College of Life Sciences, Qingdao Agricultural University, Key Lab of Plant Biotechnology in Shandong \\ Province, No. 700 Changcheng Road, Chengyang, Qingdao, Shandong, P. R. China, P.C. 266109 \\ (Received August 11, 2015; Accepted October 27, 2015)
}

\begin{abstract}
Microwave-assisted three-liquid-phase extraction (MATLPE) was applied to extract diosgenin and untransformed saponins in Dioscorea zingiberensis C. H. Wright (DZW) fermentation broth from Trichoderma harzianum. The partitioning behaviours of various steroids were investigated, and the removal of soluble protein, microbial cells and raw herb residuals were studied. A three-liquid-phase system (TLPS) consisting of 30\% (w/w) ethanol, $15 \%(\mathrm{w} / \mathrm{w})\left(\mathrm{NH}_{4}\right)_{2} \mathrm{SO}_{4}, 40 \%(\mathrm{w} / \mathrm{w})$ petroleum ether and water was selected. The optimal microwave extraction parameters were as follows: liquid/solid ratio, 80:1; microwave time, $120 \mathrm{~s}$; and microwave power, $380 \mathrm{~W}$. MATLPE integrated the extraction and separation of diosgenin and the untransformed saponins, the separation of solids and liquids, and the removal of soluble impurities (reducing sugars and proteins) in one step. Compared with other methods, MATLPE consumed smaller amounts of reagents, achieved higher recoveries, and resulted in several-fold higher concentrations of diosgenin and saponin extracts.
\end{abstract}

\section{Introduction}

Diosgenin, an important starting material in the partial synthesis of steroid hormones, is generally obtained from the roots of plants of the genus Dioscorea [1, 2]. Dioscorea zingiberensis C. H. Wright (DZW) is among the most important resources for diosgenin production. In industry, diosgenin is mainly prepared by acid hydrolysis of DZW tubers. However, this is not an environmentally friendly approach because other components in plant herbs are degraded into small molecular compounds, resulting in a high chemical oxygen demand (COD, 50,000-80,000 mg/L) and high concentrations of $\mathrm{SO}_{4}{ }^{2-}(29,700-46,200$ $\mathrm{mg} / \mathrm{L})$ and acid $\left(\mathrm{H}^{+}, 1.1-1.2 \mathrm{~mol} / \mathrm{L}\right)$ in large amounts of wastewater [3, 4]. Moreover, the structure of diosgenin is damaged by high acidity, which leads to lower yields. Alternatively, microbial transformation is environmentally friendly and requires mild conditions [5]. Recently, the microbial transformation of diosgenin from the corresponding glycosidal form of steroidal saponin in plant tissues has been proposed as an alternative to traditional acid hydrolysis, which generates serious pollution [6-8]. Due to its high selectivity and mild reaction conditions, microbial transformation provides a high yield of diosgenin. At the same time, substantial amounts of steroidal saponins are obtained as by-products, which possess many biological activities, such as cytotoxicity and anticancer and antifungal activity [9-12]. In industrial production, petroleum ether is used to extract diosgenin after acid hydrolysis of DZW [13]. However, the extraction process is costly in terms of energy and time. Diosgenin preparation using bio-pretreatment 
followed by supercritical fluid extraction has been reported [4, 14], but the large investment in equipment has limited its large-scale application. Moreover, the above reported technologies cannot extract diosgenin and various steroidal saponins simultaneously: saponins remain in the raw herb residuals.

Microwave-assisted extraction (MAE) has been used to extract many biologically active compounds, such as carotenoids from carrot peels [15] and anthocyanins from blackberries [16]. The MAE system rapidly generates heat, resulting in shorter extraction times and good quality extracts with better target compound recovery $[17,18]$. The microwave-assisted aqueous two-phase extraction (MAATPE) of total steroids in culture broth yielded by the fermentation of DZW in an ethanol/ammonium sulphate system has been studied by our group. The improved MAATPE method allowed for the recovery of high levels of diosgenin (97.14\%) and total saponins (96.77\%) [19]. However, this method is uneconomical and cumbersome. Large amounts of reagents, such as ethanol, salt and water, are consumed, and two stirring steps and multiple microwave heating steps are needed. Moreover, after extraction, all steroids (saponins and diosgenin) are concentrated in the same phase (ethanol phase). To obtain the final product, diosgenin must be separated. Hence, an extraction technology that is more suitable for the simultaneous extraction and separation of diosgenin and steroidal saponins, especially from fermentation broth, is required.

Three-liquid-phase extraction is a technique developed for the separation of multi-component mixtures because of its unique separation selectivity. The technique involves three coexisting liquid phases with different physicochemical properties [20, 21]. Three-liquid-phase systems (TLPSs) composed of organic solvents, polymers, inorganic salts and water have been employed for the separation of various components, such as phenol and $p$-nitrophenol [22]; glycyrrhizic acid and liquiritin [23]; $p$-nitrophenol and $o$-nitrophenol [24]; and multi-metals [25, 26]. A TLPS composed of an organic solvent, a short-chain alcohol, an inorganic salt, and water has many advantages over traditional TLPSs, such as low cost and easy recovery of alcohol by evaporation.

In this work, TLPS and MAE were integrated, and this microwave-assisted three-liquid-phase extraction (MATLPE) technology was used to extract diosgenin and untransformed steroidal saponins from a DZW fermentation broth of Trichoderma harzianum. Furthermore, the partitioning behaviours of diosgenin and various steroidal saponins in the TLPS were studied. The most important parameters involved in the MATLPE process were optimized by single-factor experiments. During the extraction process, diosgenin and various saponins were distributed into different phases of the TLPS, and microbial cells, raw herb residues, and other soluble impurities, such as proteins and reducing sugars, could be removed. The amount of reagents consumed by this extraction technology is greatly reduced compared with that consumed by the previously reported method of improved MAATPE. To the best of our knowledge, this work represents the first application of MATLPE.

\section{Experimental}

\subsection{Materials}

The fermentation broth was obtained from the biotransformation of DZW dried root powder under optimized conditions, as described previously [8]. T. harzianum is preserved at the China General Microbiological Culture Collection Centre (CGMCC, No. 2979, Beijing, China). Diosgenin and the standards for the steroidal saponins have been described in a previous publication [19]. The total steroid 
extract, from which precipitates, including cells and raw herb residuals, were removed, was prepared according to a previously described method [19]. Diosgenin was the major component of the extract at 1.72 $\mathrm{mmol} / \mathrm{L}$, and it contained the following five additional steroidal saponins: zingiberensis newsaponin, deltonin, diosgenin-triglucoside, diosgenin-diglucoside and trillin (Figure 1). All other chemicals were of analytical grade.

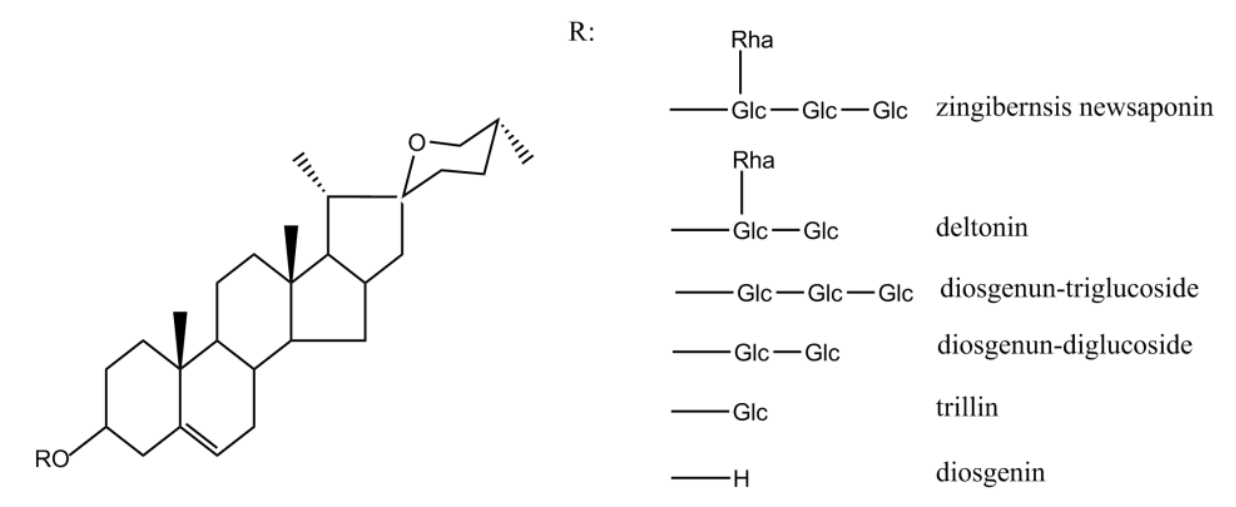

Figure 1. Structures of steroids.

\subsection{Effects of the ammonium sulphate and ethanol concentrations on the partition coefficients of various steroids in the TLPS}

Based on the phase diagram of petroleum ether/ethanol/ $\left(\mathrm{NH}_{4}\right)_{2} \mathrm{SO}_{4}[19]$, ethanol concentrations of $20 \%(\mathrm{w} / \mathrm{w}), 25 \%(\mathrm{w} / \mathrm{w})$ and $30 \%(\mathrm{w} / \mathrm{w})$ were selected. At each ethanol concentration, the ammonium sulphate concentration ranged from the split-phase point (ammonium sulphate additive level below which no aqueous two-phase system could be formed) to the salting-out point (additive level above which the ammonium sulphate would precipitate). Our previous study has shown that the recovery of diosgenin increases significantly with increasing concentrations of petroleum ether from $20 \%(\mathrm{w} / \mathrm{w})$ to $40 \%(\mathrm{w} / \mathrm{w})$ and that it remains unchanged beyond $40 \%(\mathrm{w} / \mathrm{w})$; these results indicate that $40 \%(\mathrm{w} / \mathrm{w})$ petroleum ether is sufficient for the concentration of diosgenin in the top phase [19]. Thus, the amount of petroleum ether added in the TLPS was $40 \%$ (w/w) of the total weight of the ATPS (Aqueous two-phase system).

The TLPS was composed of ethanol $(20 \%, 25 \%$ or $30 \%(\mathrm{w} / \mathrm{w}))$, ammonium sulphate $(13 \%-26 \%$, $\mathrm{w} / \mathrm{w})$, and petroleum ether $(40 \%, \mathrm{w} / \mathrm{w})$. For the formation of the TLPS, ammonium sulphate, ethanol, water and the total steroid extract (prepared as in section 2.1) were first mixed to form the ATPS, weighing $8 \mathrm{~g}$. Then petroleum ether was added into the ATPS to form the TLPS. The TLPS was maintained at room temperature for $0.5 \mathrm{~h}$, and $400 \mu \mathrm{L}$ of the top phase was evaporated to remove the petroleum ether layer. The residue was then dissolved in an equal volume of anhydrous methanol for HPLC analysis. Four hundred microlitres each of the middle and bottom phases were added to two volumes of anhydrous methanol, and the mixture was vigorously mixed by inversion and then centrifuged at 12,000 rpm for $15 \mathrm{~min}$. The supernatant was collected and analysed by analytical HPLC [8]. The samples were analysed with a Waters 600E multi-solvent delivery system (Agilent, America) equipped with a Sunfire C18 column, $4.6 \mathrm{~mm} \times 150 \mathrm{~mm}(5 \mu \mathrm{m}$, Waters, the United Kingdom), and a Waters 2487 detector at $203 \mathrm{~nm}$. The eluent consisted of acetonitrile (A) and $\mathrm{H}_{2} \mathrm{O}$ (B) with the following gradient elution program: 0-14 min, 
$44 \% \mathrm{~A} \rightarrow 75 \% \mathrm{~A} ; 14-15 \mathrm{~min}, 75 \% \mathrm{~A} \rightarrow 91 \% \mathrm{~A}$; and $15-32 \mathrm{~min}, 91 \% \mathrm{~A}$. The flow rate of the mobile phase was $1.0 \mathrm{~mL} / \mathrm{min}$, and the column was eluted at room temperature.

The partition coefficient $K_{m / b}$ is the ratio of the saponin concentration in the middle phase to that in the bottom phase. $K_{t / m / b}$ is the ratio of the saponin concentration in the top phase to that in the middle and bottom phases, and the concentration in the bottom phase is defined as 1 . The partition coefficient $K_{t / m}$ is the ratio of the diosgenin concentration in the top phase to that in the middle phase. The recoveries of diosgenin and each saponin are calculated according to equations (1) and (2), respectively:

$$
\begin{aligned}
& \text { Recovery }_{\text {diosgenin }}=\frac{C_{t} \times V_{t}}{C_{t} \times V_{t}+C_{m} \times V_{m}} \\
& \text { Recovery }_{\text {saponin }}=\frac{C_{m} \times V_{m}}{C_{t} \times V_{t}+C_{m} \times V_{m}+C_{b} \times V_{b}}
\end{aligned}
$$

where $C_{b}, C_{m}$ and $C_{b}$ represent the steroid concentrations in the top, middle and bottom phases, respectively, and $V_{t}, V_{m}$ and $V_{b}$ represent the volumes of the top, middle and bottom phases, respectively.

\subsection{Removal of cells, raw herb residuals, and soluble proteins}

After fermentation, ammonium sulphate, ethanol, water and petroleum ether were added directly into a $250 \mathrm{~mL}$ Erlenmeyer flask (with $30 \mathrm{~mL}$ of fermentation broth) to form the TLPS, which weighed $84 \mathrm{~g}$. In the TLPS, the concentrations of ethanol, ammonium sulphate, and petroleum ether were $20-25 \%(\mathrm{w} / \mathrm{w})$, $13-26 \%(\mathrm{w} / \mathrm{w})$ and $40 \%(\mathrm{w} / \mathrm{w})$, respectively. The mixture was stirred for $5 \mathrm{~min}$ and held for $0.5 \mathrm{~h}$ at room temperature. The protein concentration was determined with bovine serum albumin (BSA) as the standard, using the method described by Bradford [27]. The tested sample was filtered under vacuum, and the filter cake (cells and raw herb residuals) was collected and dried at $60^{\circ} \mathrm{C}$ for $12 \mathrm{~h}$. Cells and raw herb residuals were then analysed by weighing. The removal rate was expressed as the ratio of cells and raw herb residuals or proteins removed from the top and middle phases to the total amount in the TLPS.

\subsection{MATLPE}

For MATLPE, $30 \mathrm{~mL}$ of culture broth obtained from the fermentation of $1 \mathrm{~g}$ DZW powder was mixed with water, $\left(\mathrm{NH}_{4}\right)_{2} \mathrm{SO}_{4}$, ethanol and petroleum ether in a flask, which was then placed in a household microwave oven and irradiated. Due to their relatively low boiling points $\left(<90^{\circ} \mathrm{C}\right)$, petroleum ether and ethanol evaporate upon microwave heating; the microwave oven was therefore equipped with three outside condensers in series. After MATLPE, the mixture was cooled for $0.5 \mathrm{~h}$ to room temperature, and the middle and top phases were analysed by HPLC. The main variables affecting MAE, the nature of the solvent, solvent volume, microwave power, and irradiation time, were optimized for the MATLPE [28]. The recovery of diosgenin is defined as the ratio of the amount (in moles) of diosgenin in the top phase to that in the broth. The recovery of each saponin is defined as the ratio of the amount of the specific saponin in the middle phase to that in the broth. The recovery of total saponins is defined as the ratio of the amount of all steroidal saponins in the middle phase to that in the broth. The amounts of diosgenin and each saponin in the broth were determined by Soxhlet extraction with petroleum ether and $70 \%$ (v/v) ethanol, respectively, at $90^{\circ} \mathrm{C}$ for $4 \mathrm{~h}[6]$.

\section{Results and Discussion}

3.1 Effects of the ammonium sulphate and ethanol concentrations on the partitioning behaviours of 


\section{various steroids in the TLPS}

The effects of the ethanol and $\left(\mathrm{NH}_{4}\right)_{2} \mathrm{SO}_{4}$ concentrations on the partition coefficients of various steroids are shown in Table 1, which shows that the partition coefficients of the various steroids were closely related to the ammonium sulphate and ethanol concentrations. Due to the enhanced salting-out effect, an increased $\left(\mathrm{NH}_{4}\right)_{2} \mathrm{SO}_{4}$ concentration enhances the ethanol concentration in the middle phase [29]. Therefore, at a fixed ethanol concentration, the partition coefficients of various saponins increased with an increasing $\left(\mathrm{NH}_{4}\right)_{2} \mathrm{SO}_{4}$ concentration. In contrast, the partition coefficients of diosgenin decreased with increasing $\left(\mathrm{NH}_{4}\right)_{2} \mathrm{SO}_{4}$ concentration at a fixed ethanol concentration. A similar phenomenon was observed with the increase in the ethanol concentration. A higher ethanol mass fraction decreases the polarity of the middle phase solvent, benefitting the enrichment of various saponins in the middle phase. However, by decreasing the solvent polarity of the middle phase, the polar gap between the middle-phase solvent and top-phase solvent (petroleum ether) was reduced, which caused diosgenin to be difficult to concentrate in the top phase. Thus, lower partition coefficients of diosgenin were observed.

Table 1. Effects of $\left(\mathrm{NH}_{4}\right)_{2} \mathrm{SO}_{4}$ and ethanol concentrations on the partition coefficients of various steroids.

\begin{tabular}{cccccccc}
\hline $\begin{array}{c}\text { Ethanol } \\
(\mathrm{w} / \mathrm{w}, \%)\end{array}$ & $\begin{array}{c}\left.\mathrm{NH}_{4}\right)_{2} \mathrm{SO}_{4} \\
(\mathrm{w} / \mathrm{w}, \%)\end{array}$ & $\begin{array}{c}\text { Zingiberensis } \\
\text { newsaponins } \\
K_{m / b}\end{array}$ & $\begin{array}{c}\text { Deltonin } \\
K_{m / b}\end{array}$ & $\begin{array}{c}\text { Diosgenin } \\
\text { triglucoside } \\
K_{t / m / b}\end{array}$ & $\begin{array}{c}\text { Diosgenin } \\
\text { diglucoside } \\
K_{t / m} / b\end{array}$ & Trillin & $\begin{array}{c}\text { Diosgenin } \\
K_{t / m}\end{array}$ \\
\hline & 20 & $7.0 \pm 0.2$ & $17.2 \pm 0.1$ & $0.9 / 12.1 / 1.0$ & $0.7 / 10.1 / 1.0$ & $12.8 \pm 0.2$ & $28.4 \pm 0.1$ \\
& 22 & $726.2 \pm 3.5$ & $1339.1 \pm 5.2$ & $1.2 / 59.8 / 1.0$ & $1.0 / 44.8 / 1.0$ & $25.9 \pm 1.1$ & $17.5 \pm 0.1$ \\
20 & 23 & $\infty$ & $\infty$ & $1.5 / 86.1 / 1.0$ & $1.4 / 95.5 / 1.0$ & $28.7 \pm 0.2$ & $5.3 \pm 0.1$ \\
& 24 & $\infty$ & $\infty$ & $1.8 / 126.5 / 1.0$ & $2.1 / 137.2 / 1.0$ & $31.7 \pm 0.2$ & $3.8 \pm 0.1$ \\
& 26 & $\infty$ & $\infty$ & $2.2 / 315.4 / 1.0$ & $2.6 / 209.7 / 1.0$ & $42.8 \pm 0.2$ & $0.9 \pm 0.1$ \\
\hline \multirow{3}{*}{25} & 17 & $20.9 \pm 0.1$ & $28.6 \pm 0.1$ & $1.2 / 25.6 / 1.0$ & $1.0 / 30.3 / 1.0$ & $1.1 / 12.1 / 1.0$ & $25.2 \pm 0.1$ \\
& 18 & $68.3 \pm 0.1$ & $49.8 \pm 0.2$ & $2.3 / 65.3 / 1.0$ & $1.2 / 44.7 / 1.0$ & $1.5 / 42.7 / 1.0$ & $11.8 \pm 0.1$ \\
& 19 & $79.1 \pm 0.2$ & $88.5 \pm 0.2$ & $2.9 / 102.4 / 1.0$ & $1.8 / 64.5 / 1.0$ & $1.8 / 60.2 / 1.0$ & $5.3 \pm 0.1$ \\
& 20 & $222.8 \pm 1.3$ & $168.5 \pm 1.1$ & $3.1 / 194.3 / 1.0$ & $2.2 / 80.6 / 1.0$ & $2.0 / 70.9 / 1.0$ & $3.6 \pm 0.1$ \\
& 22 & $\infty$ & $\infty$ & $3.4 / 312.3 / 1.0$ & $2.9 / 113.5 / 1.0$ & $3.3 / 114.8 / 1.0$ & $1.6 \pm 0.1$ \\
\hline \multirow{3}{*}{30} & 13 & $8.4 \pm 0.1$ & $14.6 \pm 0.2$ & $1.5 / 32.9 / 1.0$ & $1.6 / 30.4 / 1.0$ & $2.4 / 25.0 / 1.0$ & $17.9 \pm 0.1$ \\
& 15 & $32.1 \pm 0.2$ & $35.9 \pm 0.2$ & $1.9 / 66.4 / 1.0$ & $1.9 / 46.5 / 1.0$ & $2.9 / 51.2 / 1.0$ & $10.6 \pm 0.1$ \\
& 17 & $\infty$ & $305.6 \pm 2.1$ & $2.1 / 142.3 / 1.0$ & $2.2 / 165.3 / 1.0$ & $3.2 / 74.6 / 1.0$ & $2.1 \pm 0.1$ \\
& 18 & $\infty$ & $\infty$ & $2.4 / 209.5 / 1.0$ & $3.0 / 251.1 / 1.0$ & $4.3 / 106.5 / 1.0$ & $1.2 \pm 0.1$ \\
& 19 & $\infty$ & $\infty$ & $2.8 / 288.1 / 1.0$ & $3.3 / 342.9 / 1.0$ & $4.7 / 130.1 / 1.0$ & $1.1 \pm 0.1$ \\
& 20 & $\infty$ & $\infty$ & $3.0 / 489.7 / 1.0$ & $3.7 / 453.3 / 1.0$ & $5.1 / 162.4 / 1.0$ & $0.9 \pm 0.1$ \\
\hline
\end{tabular}

For the subscripts, $t$ represents the top phase, $m$ represents the middle phase, and $b$ represents the bottom phase. At ethanol concentrations of $20 \%$ or $25 \%$ (or $30 \%$ ), the partition coefficients for trillin are indicated by $K_{m / t}$ and $K_{t / m / b}$, respectively (n=3).

As shown in Figure 2, a high recovery of various saponins and diosgenin was achieved in the middle and top phases, respectively, indicating that saponins tended to concentrate in the middle phase, whereas diosgenin tended to concentrate in the top phase. Due to the presence of a number of sugar residues linked 
to the steroid skeleton [30], various steroids possess different polarities. The five steroidal saponins have stronger polarities, whereas diosgenin has a remarkably weak polarity. The solvent polarities in the different phases of the TLPS were appropriate for the dissolution of different steroids, resulting in the separation of diosgenin and untransformed saponins.

\subsection{Effects of the ammonium} sulphate and ethanol concentrations on the degree of removal of cells, raw herb

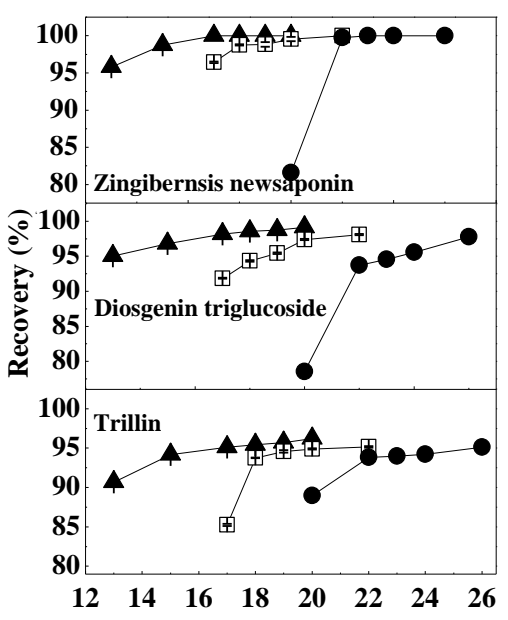

Concentration of $\left(\mathrm{NH}_{4}\right)_{2} \mathrm{SO}_{4}(\mathrm{w} / \mathrm{w}, \%)$

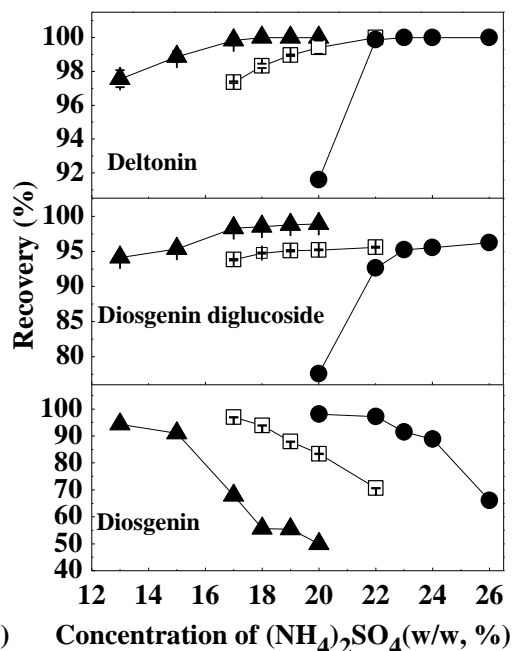

$30 \%(w / w)$ Ethanol $\square-25 \%(w / w)$ Ethanol

$-20 \%(w / w)$ Ethanol

Figure 2. Effects of the $\left(\mathrm{NH}_{4}\right)_{2} \mathrm{SO}_{4}$ and ethanol concentrations on the recoveries of various steroids in the TLPS.

\section{residuals, and soluble protein}

Ammonium sulphate and ethanol are usually used as precipitating agents for proteins in aqueous two-phase systems [31, 32]. When the DZW fermentation broth was used directly for the formation of the TLPS, proteins were concentrated at the interface between the middle and bottom phases. Previous studies have also shown that ATPS can be used to separate cells and biomolecules from fermentation broth, as most of the cells and biomolecules partition in the interphase [33, 34]. In the TLPS, microbial cells and raw herb residuals were also concentrated at the interface between the middle phase and the bottom phase. The effects of the ammonium sulphate and ethanol concentrations on the removal of soluble protein and the total removal of cells and raw herb residuals are shown in Figure 3. The total removal of cells and raw herb residuals was greater than $99.13 \pm 0.11 \%$, and few differences were observed with changes in the $\left(\mathrm{NH}_{4}\right)_{2} \mathrm{SO}_{4}$ or ethanol concentration. At a fixed ethanol concentration with an increasing $\left(\mathrm{NH}_{4}\right)_{2} \mathrm{SO}_{4}$ concentration, the removal of soluble protein increased. Although the

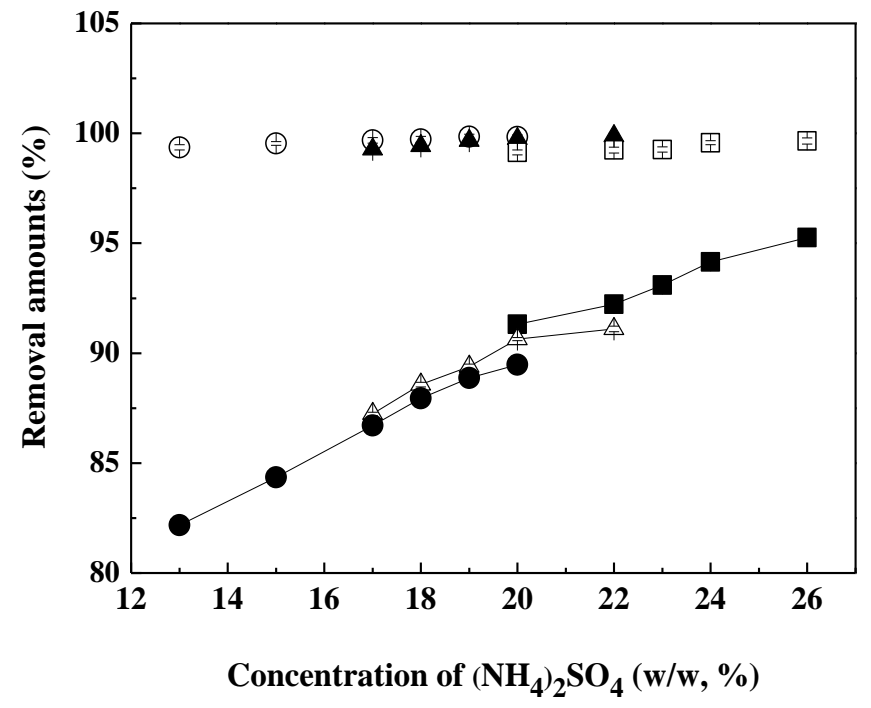

Figure 3. Effects of the $\left(\mathrm{NH}_{4}\right)_{2} \mathrm{SO}_{4}$ and ethanol concentrations on the removal of cells, raw herb residuals and soluble proteins. Symbols: removal of protein at $30 \%(\mathrm{w} / \mathrm{w})$ ethanol $(\bullet), 25 \%(\mathrm{w} / \mathrm{w})$ ethanol $(\Delta)$, and $20 \%(\mathrm{w} / \mathrm{w})$ ethanol $(\boldsymbol{m})$; total removal of microbial cells and raw herb residuals at $30 \%(\mathrm{w} / \mathrm{w})$ ethanol (०), 25\% (w/w) ethanol $(\mathbf{\Delta})$ and $20 \%(\mathrm{w} / \mathrm{w})$. 
removal of protein decreased with an increasing ethanol concentration, the total removal of soluble protein was greater than $82.17 \pm 0.14 \%$. Hydrophobic interactions probably play a major role in protein fractionation because the phase hydrophobicity effect is directly related to the chemical identities of constituents in a system, as well as their concentrations [35, 36]. Louwrier [37] has reported that $\mathrm{pH}$ is an important factor affecting protein partitioning. In the TLPSs, the $\mathrm{pH}$ of the $\left(\mathrm{NH}_{4}\right)_{2} \mathrm{SO}_{4}$ phase was 5.38-6.51, and a significant $\mathrm{pH}$ change was not observed. It appears that $\mathrm{pH}$ was not a crucial factor influencing protein precipitation.

\subsection{Optimization of MATLPE}

\subsubsection{Optimal phase composition}

MATLPE was performed for the extraction and separation of diosgenin and untransformed steroidal saponins in DZW fermentation broth. Based on the findings of the distributional regulation of the steroids and the removal of soluble protein, four TLPSs were used to extract the steroids in the culture broth. In the four selected TLPSs, various saponins and diosgenin were separated efficiently, and raw herb residuals, cells and proteins were eliminated with high removal levels. The operational parameters were as follows: extraction time, $120 \mathrm{~s}$; extraction power, $380 \mathrm{~W}$; and liquid/solid ratio, 80:1. The effects of phase composition on the recoveries of diosgenin and total saponin are shown in Figure 4a. The volume of each

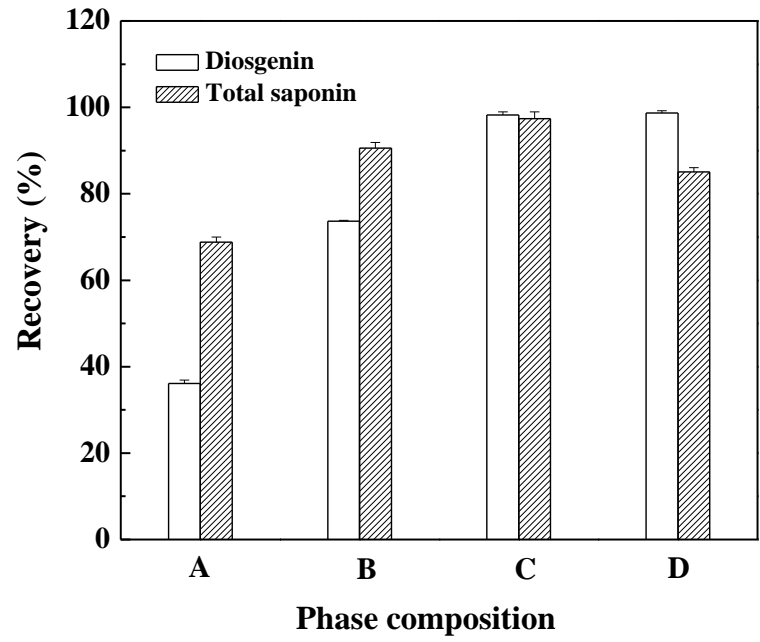

a

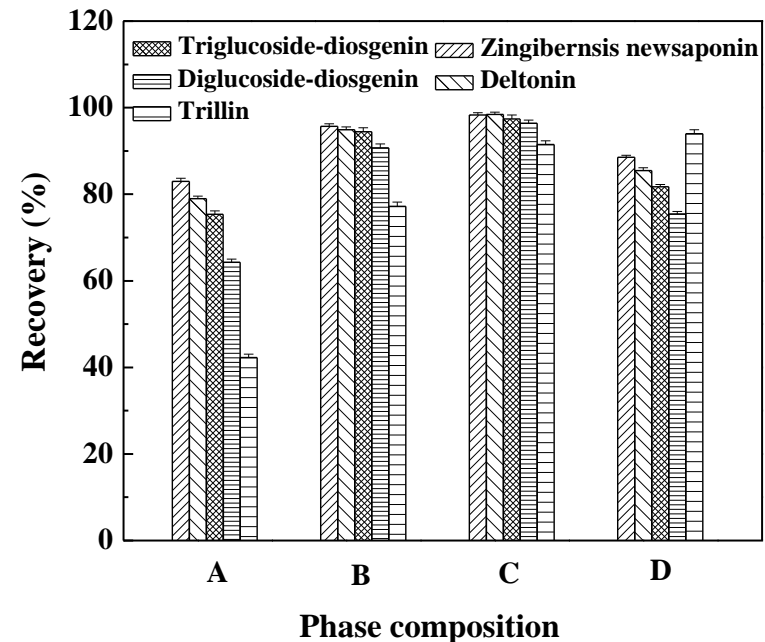

b

Figure 4. Effects of phase composition on steroid yield. a Yields of diosgenin and total saponin in MATLPE. b Yields of various saponins in MATLPE. A $20 \%(\mathrm{w} / \mathrm{w})$ ethanol, $23 \%(\mathrm{w} / \mathrm{w})\left(\mathrm{NH}_{4}\right)_{2} \mathrm{SO}_{4}$ and $40 \%(\mathrm{w} / \mathrm{w})$ petroleum ether; volumes of top, middle and bottom phases were 33.0, 15.0 and $40.0 \mathrm{~mL}$, respectively. B 25\% (w/w) ethanol, $18 \%(\mathrm{w} / \mathrm{w})\left(\mathrm{NH}_{4}\right)_{2} \mathrm{SO}_{4}$ and $40 \%(\mathrm{w} / \mathrm{w})$ petroleum ether; volumes of top, middle and bottom phases were 34.0, 35.5 and $21.6 \mathrm{~mL}$, respectively. C 30\% (w/w) ethanol, $15 \%$ (w/w) $\left(\mathrm{NH}_{4}\right)_{2} \mathrm{SO}_{4}$ and $40 \%$ (w/w) petroleum ether; volumes of top, middle and bottom phases were 34.0, 36.0 and $22.0 \mathrm{~mL}$, respectively. D 35\% (w/w) ethanol, $13 \%(\mathrm{w} / \mathrm{w})\left(\mathrm{NH}_{4}\right)_{2} \mathrm{SO}_{4}$ and $40 \%(\mathrm{w} / \mathrm{w})$ petroleum ether; volumes of top, middle and bottom phases were $34.0,40.0$ and $17.0 \mathrm{~mL}$, respectively. 
phase in the TLPSs used in MATLPE is shown in the caption of Figure 4a. The recovery of diosgenin increased with increasing ethanol mass fraction. The TLPS containing 30\% (w/w) ethanol achieved a high diosgenin recovery of $98.27 \pm 0.71 \%$. Upon increasing the ethanol concentration to $35 \%$, only a slight increase (less than $0.5 \%$ ) in diosgenin recovery $(98.73 \pm 0.52 \%)$ was observed. The recovery of total saponin increased with increasing ethanol mass fraction of up to $30 \%(\mathrm{w} / \mathrm{w})$. Increasing the ethanol concentration further to $35 \%(\mathrm{w} / \mathrm{w})$ led to a $12.38 \%$ decrease in total saponin recovery. The highest recovery of total saponins $(97.42 \pm 1.51 \%)$ was obtained in the TLPS containing $30 \%(\mathrm{w} / \mathrm{w})$ ethanol. Therefore, the phase composition of $30 \%(\mathrm{w} / \mathrm{w})$ ethanol, $15 \%(\mathrm{w} / \mathrm{w})\left(\mathrm{NH}_{4}\right)_{2} \mathrm{SO}_{4}$, and $40 \%(\mathrm{w} / \mathrm{w})$ petroleum ether was selected as the optimal phase composition for MATLPE. The effects of phase composition on the recovery of various saponins are shown in Figure 4b. The effect of phase composition on the recovery of trillin was similar to that of diosgenin, which could be attributed to the weak polarity of trillin. Structurally, trillin has only one additional glucose residue than diosgenin. With increasing ethanol concentration, the changing trends of the recoveries of various saponins, including zingiberensis newsaponin, deltonin, diosgenin-triglucoside, and diosgenin-diglucoside, were the same as that observed for total saponins. The above mentioned results indicated that the ethanol concentration was the most important factor affecting the recovery of various steroids. A high ethanol concentration is beneficial to diosgenin extraction but is not suitable for the extraction of steroidal saponins, which could also be attributed to the polarity differences of the various steroids.

\subsubsection{Optimal liquid/solid ratio}

Appropriate quantities of $\left(\mathrm{NH}_{4}\right)_{2} \mathrm{SO}_{4}$, ethanol, petroleum ether and water were added to the culture broth (approximately $30 \mathrm{~mL}$, obtained from the fermentation of 1 $\mathrm{g}$ of DZW powder) to form TLPSs with weights of $60 \mathrm{~g}, 80 \mathrm{~g}, 100 \mathrm{~g}$, and $120 \mathrm{~g}$, respectively. The weight represented the total weight of all solvents and broth. Other parameters were as follows: optimal phase composition, extraction time of $120 \mathrm{~s}$ and extraction power of $380 \mathrm{~W}$. The effects of the liquid/solid ratio on the recoveries of diosgenin, total saponins and the various saponins are shown in Figure 5. The volume of each phase in the TLPSs used in MATLPE is shown in the caption of Figure 5. The recoveries of the various saponins exhibited regularity similar to the recoveries of diosgenin and total saponins. Upon increasing the liquid/solid ratio from 60:1 to $80: 1$, the recoveries of diosgenin

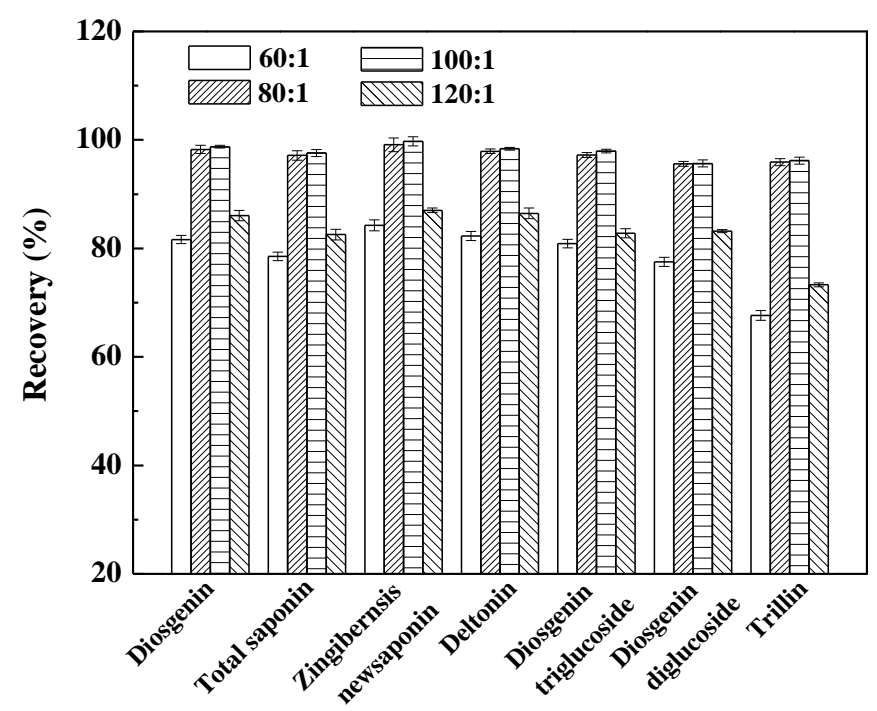

Figure 5. Effects of the liquid/solid ratio on the recoveries of diosgenin, total saponins and various saponins in MATLPE. Liquid/solid ratio 60:1: volumes of top, middle and bottom phases were 27.0, 26.2, and $16.0 \mathrm{~mL}$, respectively; liquid/solid ratio 80:1: volumes of top, middle and bottom phases were $34.0,35.5$, and $21.6 \mathrm{~mL}$, respectively; liquid/solid ratio 100:1: volumes of top, middle and bottom phases were 45.0, 43.0, and $26.0 \mathrm{~mL}$, respectively; liquid/solid ratio 120:1: volumes of top, middle and bottom phases were 53.0, 51.0, and $31.0 \mathrm{~mL}$, respectively. 
and total saponins increased to $98.25 \pm 0.74 \%$ and $97.14 \pm 0.85 \%$, respectively. A further increase in the liquid/solid ratio to 100:1 did not significantly change the recoveries. Beyond 100:1, further increases in the liquid/solid ratio led to decreased recoveries. The amount of extraction agent that interacted with the electromagnetic field directly affected the microwave energy transfer process [37]. Although increasing the liquid/solid ratio accelerated the mass transfer between solid and liquid and favoured steroid recovery, liquid/solid ratios in excess of 100:1 caused large amounts of heat dissipation and left only a small amount of heat to be absorbed by the mycelium and raw herb. Consequently, decreased recoveries of various steroids were observed at a liquid/solid ratio of 120:1. For the sake of economy, 80:1 was selected as the optimal liquid /solid ratio for MATLPE.

\subsubsection{Optimal irradiation power and microwave time}

The effects of differing irradiation power on the recoveries of total saponin and diosgenin were investigated. Extractions were performed at the following five operating powers: $120 \mathrm{~W}, 230 \mathrm{~W}, 380 \mathrm{~W}$, $540 \mathrm{~W}$ and $700 \mathrm{~W}$. At each power, the extraction time was studied over a range of 30-150 s. The other parameters were as follows: optimal phase composition and a liquid/solid ratio of 80:1. As shown in Figures 6 and 7, when the operating power was lower than $380 \mathrm{~W}$, the recoveries of diosgenin and total saponins increased with increasing extraction time from $30 \mathrm{~s}$ to $150 \mathrm{~s}$. A prolonged extraction time enhances the extraction temperature. At higher temperatures, cell walls are more easily destroyed, and the solubilities of target components increase. Hence, with the extension of the extraction time, the recoveries increased. Operating powers of less than $380 \mathrm{~W}$ resulted in unsatisfactory recoveries of total saponins and diosgenin, which could be attributed to incomplete heating of the target material. Low power requires an increased irradiation time to maximize the extraction of steroids. Similar results have also reported for the extraction of pharmaceuticals, personal care products and hormones by Azzouz [28]. We also found that increasing the irradiation power from $380 \mathrm{~W}$ to $700 \mathrm{~W}$ reduced the optimal extraction time (the highest recoveries of diosgenin and total saponins were obtained). Microwave power affects the transfer rate of irradiation energy, and higher microwave power results in more electromagnetic energy transferred to the extraction system [38]. At a microwave power of $380 \mathrm{~W}$, the recoveries of diosgenin and total saponins reached $98.35 \pm 1.04 \%$ and $97.38 \pm 1.13 \%$, respectively, at $120 \mathrm{~s}$. Further increasing the extraction time to $150 \mathrm{~s}$ did not significantly increase the recoveries because the active components had been almost completely extracted. At microwave powers of $540 \mathrm{~W}$ and $700 \mathrm{~W}$, the maximum recoveries were observed at $90 \mathrm{~s}$ and $60 \mathrm{~s}$, respectively. Further increasing the extraction time led to decreased recoveries because such drastic heating under high power induced solvent loss. In the experiment, the weights of the TLPSs that had been subjected to microwave powers of $540 \mathrm{~W}$ and $700 \mathrm{~W}$ for $150 \mathrm{~s}$ decreased by $3.09 \pm 0.12 \mathrm{~g}$ and $5.15 \pm 0.14 \mathrm{~g}$, respectively, compared with the original weights, whereas the weights of the TLPSs subjected to lower irradiation powers of $120 \mathrm{~W}, 230 \mathrm{~W}$ and $380 \mathrm{~W}$ did not change. The petroleum ether boiled at $60-90^{\circ} \mathrm{C}$, and the boiling point of ethanol is $78.4^{\circ} \mathrm{C}$. Thus, high microwave power combined with long extraction times would easily result in evaporation of the extraction agents. At $540 \mathrm{~W}$, the highest recoveries of total saponins and diosgenin were $98.42 \pm 115 \%$ and $97.57 \pm 1.61 \%$, respectively. At $700 \mathrm{~W}$, the highest recoveries of total saponins and diosgenin were $98.63 \pm 1.62 \%$ and $97.71 \pm 1.42 \%$, respectively. There were no significant differences between the recovery amounts (diosgenin or total saponins) at $380 \mathrm{~W}, 540$ $\mathrm{W}$ and $700 \mathrm{~W}$. Considering energy conservation, the optimal extraction conditions were determined to be 


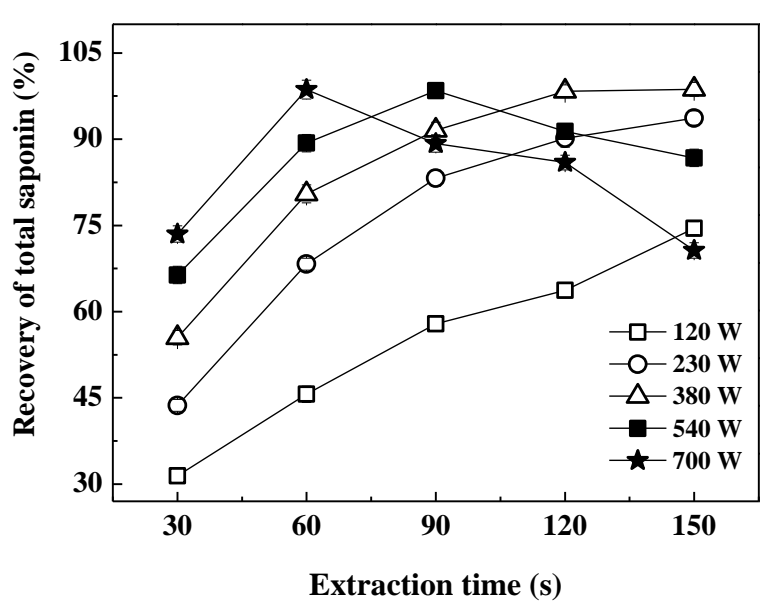

Figure 6. Effects of microwave power and extraction time on the recovery of total saponin.

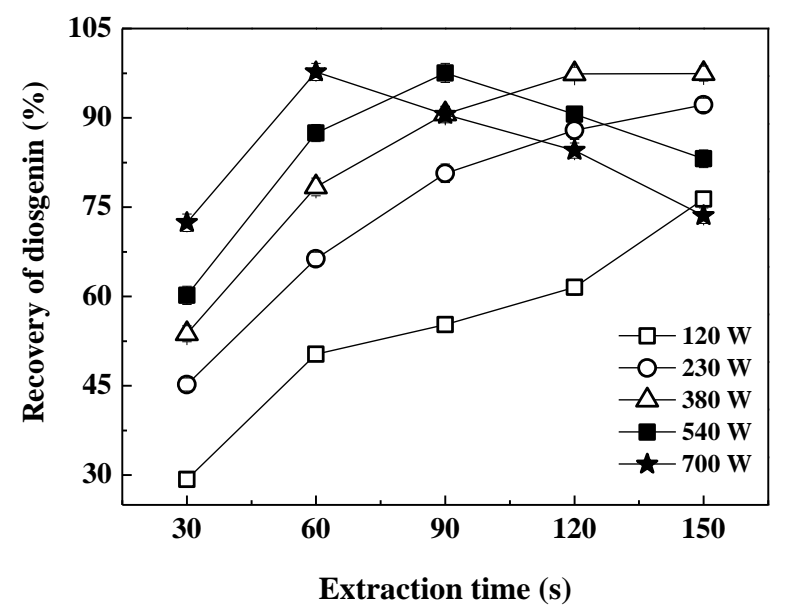

Figure 7. Effects of microwave power and extraction time on the recovery of diosgenin.

\subsection{MAE with different extraction} agents

To demonstrate the superiority of the extraction agents used in TLPS over the other agents used in MAE, six combination agents consisting of various components of the TLPS were used in MAE and compared with their use in TLPS. For the six combinations of extraction agents, the qualities of the reagents used, including petroleum ether, ethanol, $\left(\mathrm{NH}_{4}\right)_{2} \mathrm{SO}_{4}$ and water, were the same as those of the reagents used in the TLPS. Figure 8 shows the effects of the different extraction agents on the recoveries of diosgenin, total saponins and various saponins. The recoveries amounts of diosgenin and total saponins obtained from MATLPE were $98.41 \pm 0.82 \%$ and $97.62 \pm 0.70 \%$, respectively, which were higher than those obtained from the other extraction agents. For MAATPE, the recovery of total saponins was $96.14 \pm 0.89 \%$, which is comparable to that

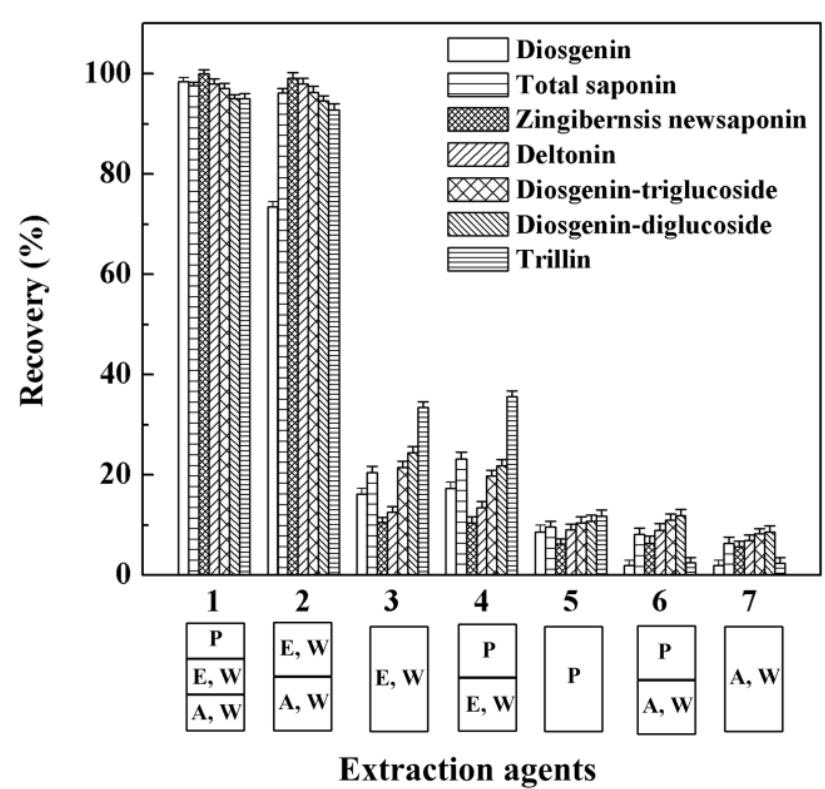

Figure 8. Effects of the extraction agents used in MAE on the recoveries of diosgenin, total saponins and various saponins. The capital letters represent the main reagents in each phase. W: water; P: petroleum ether; E: ethanol; A: $\left(\mathrm{NH}_{4}\right)_{2} \mathrm{SO}_{4} .1$ TLPS; 2 aqueous two-phase system of ethanol/ $\left(\mathrm{NH}_{4}\right)_{2} \mathrm{SO}_{4} ; 3$ aqueous ethanol solution; 4 aqueous two-phase system of petroleum ether/ethanol; 5 petroleum ether; 6 aqueous two-phase system of petroleum ether/( $\left.\mathrm{NH}_{4}\right)_{2} \mathrm{SO}_{4} ; 7$ aqueous $\left(\mathrm{NH}_{4}\right)_{2} \mathrm{SO}_{4}$. 
obtained from MATLPE. However, the recovery of diosgenin from MAATPE decreased by $24.94 \%$ to $73.47 \pm 0.97 \%$. In the aqueous two-phase system, large quantities of diosgenin and saponins were enriched in the ethanol phase, and their competitive dissolution decreased their corresponding recoveries. However, in TLPS, the phase-splitting behaviour induced the transfer of untransformed saponins and diosgenin to the ethanol and petroleum ether phases, respectively. This effect resulted in lower active component concentrations around the materials and thus accelerated the dissolution of steroids, making the extraction more thorough. Other extraction agents could not extract the steroids effectively, with diosgenin and total saponin recovery of less than $24 \%$. Recoveries of lower than $40 \%$ were obtained for the various steroids with the use of extraction agents such as an aqueous ethanol solution or a two-phase system of petroleum ether/ethanol/water, and these results may have been due to the low ethanol concentrations in these agents. Our previous study has shown that ethanol concentrations of lower than $60 \%(\mathrm{v} / \mathrm{v})$ are not suitable for the extraction of steroids from DZW [6]. These steroids are difficult to dissolve in water [39]; thus, the finding that the $\left(\mathrm{NH}_{4}\right)_{2} \mathrm{SO}_{4}$ aqueous solution achieved low recoveries is reasonable. Because of the phase-splitting behaviours in systems of petroleum ether/water and petroleum ether/ $\left(\mathrm{NH}_{4}\right)_{2} \mathrm{SO}_{4} /$ water, water in the bottom phase prevents the interaction of steroids with petroleum ether, leading to the low recoveries (less than $12 \%$ ) of various steroids. In short, compared with the other extraction agents tested, only the TLPS allowed for the effective extraction and separation of diosgenin and untransformed saponins in DZW fermentation broth.

\subsection{Comparison of MATLPE with the improved MAATPE}

In our previous publication [19], the improved MAATPE was used to extract steroids from DZW fermentation broth; the recoveries of diosgenin and total saponins were $97.14 \pm 0.52 \%$ and $96.77 \pm 0.24 \%$, respectively, which are similar to the values obtained from MATLPE. However, during operation of the improved MAATPE, $70 \mathrm{~mL}$ of ethanol must first be added to the broth for the efficient extraction of diosgenin. Thus, for the TLPS, large amounts of ammonium sulphate, petroleum ether, and water are required. Consequently, the liquid/solid ratio for the extraction was 258:1, which was much higher than the value (80:1) observed in MATLPE. As shown in Table 2, compared with the improved MAATPE, MATLPE reduced the consumption of ammonium sulphate, ethanol and water by $68.98 \%, 68.98 \%$ and $68.97 \%$,

Table 2. Comparison of MATLPE with the improved MAATPE.

\begin{tabular}{ccc}
\hline Method & MATLPE & Improved MAATPE+TLPS \\
\hline Recovery of diosgenin (\%) & $98.41 \pm 0.82$ & $97.14 \pm 0.52$ \\
Recovery of total saponin (\%) & $97.62 \pm 0.70$ & $96.77 \pm 0.24$ \\
$\left(\mathrm{NH}_{4}\right)_{2} \mathrm{SO}_{4}(\mathrm{~g})$ & 8.57 & 27.63 \\
Petroleum ether used (g) & 22.86 & 73.67 \\
Ethanol used (g) & 17.14 & 55.25 \\
Water used (g) & 31.43 & 101.29 \\
Liquid/solid ratio & $80: 1$ & $258: 1$ \\
Stir operation (times) & once & three times \\
Microwave irradiation extraction & once for $120 \mathrm{~s}$ & twice for $60 \mathrm{~s}$ \\
\hline
\end{tabular}


respectively. Moreover, two stirring steps, one for the mixing of ethanol and broth and the other for the formation of the aqueous two-phase system, were required during the improved MAATPE extraction. Each stirring process was followed by microwave heating for $60 \mathrm{~s}$. Furthermore, when petroleum ether was added to separate diosgenin from the saponins, a third stirring step was necessary. MATLPE simplified the operation by accomplishing the extraction and separation of diosgenin and untransformed saponins in one step, with one stirring step and one microwave heating treatment. In addition, the amount of petroleum ether used in MATLPE was $31.03 \%$ of the amount consumed in the separation following the improved MAATPE.

\subsection{Comparison of MATLPE with other traditional extraction methods}

Several traditional extraction methods, including Soxhlet extraction, heat reflux extraction and cold leaching extraction, were also tested and compared with MATLPE under the optimized conditions. Based on our previous study, the extraction agent used in these three methods was 70\% (v/v) ethanol [6]. Table 3 shows a comparison of the performance of MATLPE with that of the three traditional methods. In general, MATLPE was superior to the three traditional methods tested, although the recovery of total saponins by MATLPE was slightly lower than that achieved by Soxhlet extraction. In terms of time cost, MATLPE only required $0.5 \mathrm{~h}$ and $120 \mathrm{~s}$, whereas several hours or days were required for the other three methods. Moreover, compared with traditional methods, this novel technology consumed less organic solvent and favoured higher concentrations of the active components in the extract due to the phase-splitting behaviour. The amount of ethanol consumed by MATLPE was only $31.02 \%$ of that consumed by traditional methods. In TLPS, oligosaccharides and glucose were concentrated in the bottom phase [15], whereas soluble protein, cells and raw herb residuals were enriched at the interface between the middle and bottom phases. Hence, the concentration of reducing sugar $(6.73 \pm 0.07 \mathrm{mg} / \mathrm{g}$ DZW $)$ or soluble protein $(10.35 \pm 0.06 \mathrm{mg} / \mathrm{g} \mathrm{DZW})$ in the saponin extract (the middle phase) from MATLPE was much lower than that in the extract obtained by heat reflux, Soxhlet or cold leaching. No reducing sugar or protein was detected in the diosgenin extract (the top phase) from MATLPE. For MATLPE, the removal percentages of reducing sugar and soluble protein were $74.68 \pm 0.13 \%$ and $83.37 \pm 0.09 \%$, respectively; moreover, the total removal of cells and residuals was $99.48 \pm 0.03 \%$. It is very convenient that sugar, proteins, cells and raw herb materials can be

Table 3. Comparison of MATLPE with other traditional extraction methods.

\begin{tabular}{ccccc}
\hline Method & MATLPE & Soxhlet & Heat reflux & Cold leaching \\
\hline Extraction time & $120 \mathrm{~s}+0.5 \mathrm{~h}$ & $4 \mathrm{~h}$ & $4 \mathrm{~h}$ & $3 \mathrm{~d}$ \\
$\begin{array}{c}\text { Recovery of diosgenin } \\
\text { (total saponins) (\%) }\end{array}$ & $\begin{array}{c}98.41 \pm 0.82 \\
(97.62 \pm 0.70)\end{array}$ & $\begin{array}{c}82.64 \pm 1.06 \\
(100)\end{array}$ & $\begin{array}{c}80.57 \pm 0.98 \\
(92.31 \pm 0.74)\end{array}$ & $\begin{array}{c}76.28 \pm 0.84 \\
(90.15 \pm 0.63)\end{array}$ \\
$\begin{array}{c}\text { Volume of diosgenin (saponin) } \\
\text { extract (mL) }\end{array}$ & $34(35)$ & $100(100)$ & $100(100)$ & $100(100)$ \\
$\begin{array}{c}\text { Ethanol used (g) } \\
\text { Reducing sugar concentration } \\
\text { in saponin extract (mg/g }\end{array}$ & 17.14 & 55.25 & 55.25 & 55.25 \\
$\begin{array}{c}\text { DZW) } \\
\text { Protein concentration in } \\
\text { saponin extract (mg/g DZW) }\end{array}$ & $10.73 \pm 0.07$ & $18.75 \pm 0.11$ & $22.37 \pm 0.09$ & $17.18 \pm 0.10$ \\
\hline
\end{tabular}


separated from the fermentation broth. The simultaneous removal of the solid contents (cells and raw herb residuals) and the separation of steroids from the fermentation broth have economic value. Moreover, this method can remove impurities (sugar and soluble proteins) effectively, which facilitates the vaporization of diosgenin and untransformed saponins.

\section{Conclusions}

In this work, MATLPE was used for the extraction and separation of diosgenin and untransformed saponins in DZW fermentation broth by T. harzianum. In this petroleum ether/ethanol/water system, diosgenin and various saponins were concentrated in the petroleum ether-rich and ethanol-rich phases, respectively. The optimal conditions of MATLPE were as follows: phase composition of $30 \%(\mathrm{w} / \mathrm{w})$ ethanol, $15 \%(\mathrm{w} / \mathrm{w})\left(\mathrm{NH}_{4}\right)_{2} \mathrm{SO}_{4}$ and $40 \%(\mathrm{w} / \mathrm{w})$ petroleum ether; liquid/solid ratio 80:1; microwave time $120 \mathrm{~s}$; and microwave power $380 \mathrm{~W}$. The maximum recovery of diosgenin and total saponins obtained from MATLPE were $98.41 \pm 0.82 \%$ and $97.62 \pm 0.70 \%$, respectively. Compared with the improved MAATPE, MATLPE simplified the operational process and reduced the consumption of ammonium sulphate, ethanol and water by $68.98 \%, 68.98 \%$ and $68.97 \%$, respectively. The amount of petroleum ether used in MATLPE was $31.03 \%$ of the amount consumed in the separation following the improved MAATPE. In addition, no soluble protein or reducing sugars was found in the diosgenin extract. Low quantities of reducing sugars and protein were detected in the saponin extract; the percentages of soluble protein and reducing sugars removed were $83.37 \pm 0.09 \%$ and $74.68 \pm 0.13 \%$, respectively, whereas the total amounts of cells and raw herb residuals removed was $99.48 \pm 0.03 \%$. MATLPE integrated the extraction and separation of diosgenin and untransformed saponins, the separation of solids and liquids, and the removal of soluble impurities in a single step. The reagents used, including petroleum ether, ethanol and $\left(\mathrm{NH}_{4}\right)_{2} \mathrm{SO}_{4}$, could be recycled, which reduces production costs. This method is favourable for process scale-up due to the avoidance of certain complex steps, and it is also promising for the separation of different compounds in other similar complex systems.

\section{Acknowledgements}

The research was supported by the Research Foundation for Advanced Talents of Qingdao Agricultural University (6631112308). We thank Dr. Zhilong Xiu for his proposals for problems involved in the experiments. We also appreciate Dr. Wenxing Liang for his efforts in paper amending.

\section{References}

1) P. Fernandes, A. Cruz, B. Angelova, H. M. Pinheiro, J.M.S. Cabral, Enzyme. Microb. Technol., 32, 688-705 (2003).

2) R. Saunders, P.S.J. Cheetham, R. Hardman, Enzyme Microb. Technol., 8, $549-555$ (1986).

3) P. Cheng, H.Z. Zhao, B. Zhao, J. R. Ni, Bioresour. Technol., 12, 2918-2925 (2009).

4) H.Z. Zhao, P. Cheng, B. Zhao, J.R. Ni, Process Biochem., 43,1427-1431 (2008).

5) M.V. Donova, O.V. Egorova, Appl. Microbiol. Biot., 94, 1423-1447 (2012).

6) S.S. Qi, Y.S. Dong, Y.K. Zhao, Z.L. Xiu, Chromatographia., 69, 865-870 (2009).

7) Y. Zhu, J. Ni, W. Huang, Bioproc. Biosyst. Eng., 33, 647-655 (2010). 
8) L. Liu, Y.S. Dong, S.S. Qi, H. Wang, Z.L. Xiu, Appl. Microbiol. Biot., 85, 933-940 (2010).

9) C.R. Yang, Y. Zhang, M.R. Jacob, S.I. Khan, K.J. Zhang, X.C. Li, Antimicrob. Agents. CH., 50, 1710-1714 (2006).

10) M. Sautour, A.C. Mitaine-Offer, M.A. Lacaille-Dubois, J. Nat. Med., 61, 91-101 (2007).

11) I. Podolak, A. Galanty, D. Sobolewska, Phytochem. Rev., 9, 425-474 (2010).

12) Y.C. Lee, J.T. Lin, C.K. Wang, C.H. Chen, D.J. Yang, J. Food Biochem., 36, 75-85 (2012).

13) X.Y. Lu, H.Q. Zhao, J. Shenyang Pharm. Univ., 20, 465-468 (2003).

14) S.M. Ghoreishi, E. Bataghva, A.A. Dadkhah, Chem. Eng. Technol., 35, 133-141 (2012).

15) B. Hiranvarachat, S. Devahastin, J. Food Eng., 126, 17-26 (2014).

16) Y. Wen, H. Chen, X. Zhou, Q. Deng, Y. Zhao, C. Zhao, X. Gong, RSC Advances, 5, 19686-19695 (2015).

17) G. F. Barbero, M. Palma, C. G. Barroso, Anal. Chim. Acta., 578, 227-233 (2006).

18) A. Liazid, R.F. Guerrero, E. Cantos, M. Palma, C.G. Barroso, Food Chem., 3, 1238-1243 (2011).

19) L. Liu, Y.S. Dong, Z.L. Xiu, Process Biochem., 45, 752-756 (2010).

20) M. Mojski, I. Gluch, J. Anal. Chem., 51, 329-342 (1996).

21) L.H.M. Da Silva, W. Loh, Chem. Commun., 7, 787-788 (1998).

22) S.F. Shen, Z.D. Chang, H.Z. Liu, Sep. Purif. Technol., 49, 217-222 (2006).

23) S.F. Shen, Z.D. Chang, J. Liu, X.H. Sun, X. Hu, H.Z. Liu, Sep. Purif. Technol., 53, 216-223 (2007).

24) P.H. Yu, Z.D. Chang, Y.C. Ma, S.J. Wang, H.B. Cao, C. Hua, H.Z. Liu, Sep. Purif. Technol., 70, 199-206 (2009).

25) P.H. Yu, K. Huang, H.Z. Liu, K. Xie, Sep. Purif. Technol., 88, 52-60 (2012).

26) C. Zhang, K. Huang, P.H. Yu, H.Z. Liu, Sep. Purif. Technol., 108, 166-173 (2013).

27) M.M. Bradford, Anal. Biochem., 72, 248-254 (1976).

28) A. Azzouz, E. Ballesteros, Sci. Total Environ., 41, 9208-9215 ( 2012).

29) X.Q. Chen, Q.L. Dong, J.G. Yu, F.P. Jiao, J. Chem. Technol. Biot., 88, 1545-1550 (2013).

30) X.C. Li, C.R. Yang, M. Hiromichi, K. Ryoji, Y. Kazuo, Phytochemistry, 33, 465-470 (1993).

31) M. Amid, M. Shuhaimi, M.Z. Islam Sarker, M.Y. Abdul Manap, Food Chem., 132, 1382-1386 (2012).

32) A. Mehrnoush, A.M.M. Yazid, S. Mustafa, J. Chromatogr. B, 931, 17-22 (2013).

33) R.M. Banik, A. Santhiagu, B. Kanari, C. Sabarinath, S.N. Upadhyay, World J. Microb. Biot., 19, 337-348 (2003).

34) J.X. Yun, S.C. Shen, F. Chen, K.J. Yao, J. Chromatogr. B, 860, 57-62 (2007).

35) J.A. Asenjo, B.A. Andrews, J. Chromatogr. A, 1218, 8826-8835 (2011).

36) B.A. Andrews, A.S. Schmidt, J.A. Asenjo, Biotechnol. Bioeng., 90, 380-390 (2005).

37) A. Louwrier, Biotechnol. Tech., 12, 363-365 (1998).

38) D.Y. Zhang, Y.G. Zu, Y.J. Fu, W. Wang, L. Zhang, M. Luo, F.S. Mu, Sep. Purif. Technol., 102, 26-33 (2013).

39) G.J. Blackwell, R.J. Flower, F.P. Nijkamp, J.R. Vane, Brit. J. Pharmacol., 62, $79-89$ (1978). 